\title{
Quality of Life and Urban / Rural Living: Preliminary Results of a Community Survey in Italy
}

\author{
Mauro Giovanni Carta ${ }^{1, *}$, Eugenio Aguglia ${ }^{1}$, Filippo Caraci $^{2}$, Liliana Dell'Osso ${ }^{4}$, Guido Di \\ Sciascio $^{5}$, Filippo Drago ${ }^{1}$, Emilio Del Giudice ${ }^{1}$, Carlo Faravelli ${ }^{5}$, Maria Carolina Hardoy ${ }^{1}$, Maria \\ Efisia Lecca ${ }^{1}$, Maria Francesca Moro1, Salvatore Calò5 Massimo Casacchia ${ }^{6}$ Matthias Angermeyer ${ }^{1}$, \\ and Matteo Balestrieri ${ }^{3}$ \\ ${ }^{1}$ University of Cagliari, Italy \\ ${ }^{2}$ University of Udine, Italy \\ ${ }^{3}$ University of Pisa, Italy \\ ${ }^{4}$ University of Bari, Italy \\ ${ }^{5}$ University of Florence, Italy \\ ${ }^{6}$ University of L'Aquila, L'Aquila, Italy
}

\begin{abstract}
Background: The purpose of this population-based study is to examine the association between subjective quality of life and rural/urban residence in six Italian regions, including age and gender into the analysis.

Methods: Study design: community survey. Study population: Samples stratified according to sex and age, drawn from municipal records. Sample size: 4999 people 18 years and older, from seven communities within six regions of Italy. Tools: Ad-hoc form to assess basic demographic data; SF-12. Interviewers were trained psychologists or medical doctors.

Results: 3398 subjects were interviewed ( $68 \%$ of recruited sample). The mean score of SF-12 in the overall sample was $38.4 \pm 6.1$, SF-12 was higher in men than in in women (38.4 \pm 6.1 vs $37.5 \pm 5.9 \mathrm{~F}=99.18$, df 1, 3396, 3397, p<0.0001); SF-12 score decreased from the youngest to the oldest age group, with significant differences between all ages groups; men showed higher scores in all age groups. The urban/rural difference of mean scores of SF-12 did not achieve statistical significance in women. Young men with urban residence had higher SF-12 scores than their counterparts with rural residence. Maen aged 65 years and older with rural residence showed, by contrast, higher scores than men from the same age group with urban residence.
\end{abstract}

Conclusions: Men show a higher subjective quality of life than women.

1. Subjective quality of life decreases with age in both genders.

2. Men are more sensitive to urban/rural residence than women.

3. Young men live better in cities, elderly men better in rural areas.

Keywords: Quality of life, Urban/rural residence, Gender, Age, Community Survey.

\section{INTRODUCTION}

Quality of life (QOL) is a complex, abstract, and multidimensional concept. Therfore, different conceptual and operational definitions have been used in QOL studies [1,2]. QOL should not be confused with the concept of standard of living, which is based primarily on income and employment status. Instead, standard indicators of QOL include not only these dimensions but also the built environment, physical and mental health, education, recreation and leisure time, and social belonging $[1,3]$.

*Address correspondence to this author at the Mauro Giovanni Carta, Department of Public Health, University of Cagliari, Italy; Viale Merello 22, 09123 Cagliari, Italy. Tel: +393338452928/+39335499994;

E-mail:mgcarta@tiscali.it
QOL may be measured by objective as well as subjective indicators. Both approaches need a multi-dimensional concept requiring the description of several life domains and their interplay as this contributes to QOL [4-6]

For measuring of subjective QOL the perceptions of individuals play a key role. Macroscopic features relating to the economic and social situation of a society are important for putting the findings at individual level into their proper context, but the key is the subjective perception of wellbeing of a person $[5,7]$

The subjective perception of QOL has been considered of great relevance to measuring the outcomes of chronic diseases, particularly those with high impairment and a strong impact on daily life $[8,9]$. It has become central to evaluat- 
Table 1. Enrolled Sample by Centre, Sex and Rate of the Non-Interviewed (Deceased, not Contacted, or Refusal)

\begin{tabular}{|c|c|c|c|c|c|c|}
\hline Centre & Interviewed Males & Interviewed Females & Total Interviewed & Non Interviewed & Total Sample Randomized & $\begin{array}{c}\% \text { of } \\
\text { Non-Interviewed }\end{array}$ \\
\hline L'Aquila & 253 & 300 & 553 & 151 & 704 & 21.4 \\
\hline Bari & 384 & 421 & 805 & 167 & 972 & 17.2 \\
\hline Catania & 210 & 294 & 504 & 162 & 666 & 24.3 \\
\hline Florence & 266 & 422 & 688 & 158 & 846 & 18.9 \\
\hline Sulcis (Sardinia) & 108 & 198 & 306 & 159 & 465 & 34.1 \\
\hline Pisa & 60 & 94 & 154 & 310 & 464 & 66.8 \\
\hline Udine & 156 & 232 & 388 & 494 & 882 & 56.0 \\
\hline Total & 1437 & 1961 & 3398 & 1601 & 4999 & 32.0 \\
\hline
\end{tabular}

ing the effectiveness of treatments as well, but more recently QOL has been used to compare living conditions and life satisfaction related to living environment [10-12].

In the past few years, increasing attention has been given to the role of place in shaping people's QOL. However, most of the theoretical work on QOL and health has been based on studies originating from urban environments and only few studies were focused on comparing the perception of QOL in urban and rural areas [13].

The purpose of this population-based study is to examine the association between subject QOL and rural/urban residence in six Italian regions, including into the analysis age and gender of participants.

\section{METHODS}

\section{Design}

The study is a community survey. Face-to-face interviews were carried out at the candidates' homes.

\section{Recruitment Methods and Study Sample}

The study sample was randomly drawn from municipal records of seven different areas in Italy including different locations with wide variations in socioeconomic conditions. These included: Sicily, Sardinia, Puglia in the South, Abruzzo in central Italy and Tuscany and Friuli-Venezia Giulia in northern Italy. In each region, an urban area and at least one rural sub-area were selected. The urban sub-areas were Iglesias in Sulcis (Sardinia), Catania in Sicily, Bari in Puglia, Sesto Fiorentino in Tuscany and Udine in FriuliVenezia Giulia.

In each region a third of the sample was drawn from municipalities with less than 10,000 inhabitants. Municipalities with less than 10,000 inhabitants and outside of metropolitan areas were defined as rural.

Randomisation was performed after stratification by sex and four different age groups (18-24; 25-44; 45-64; >64).

Using the above mentioned methodology, a sample of 4999 people, aged 18 years and older, was drawn from the seven centers. The size of samples was: 704 in L'Aquila; 971 in Bari; 666 in Catania; 465 in Sulcis; 882 in Udine, 464 in Pisa and 846 in Florence (1310 in Tuscany).

For each person in the sample his or her general practitioner's name was recorded, which was obtained from the general practitioner's health authority registry (practically each Italian resident is registered with a general practitioner). The general practitioners were asked to sign an invitation to their patients for survey collaboration.

Subjects were contacted at home by phone and by mail by the local coordinator of the study.

\section{Interview, Tools and Study Assessment}

Interviews consisted of the following tools:

1. Basic demographic data were assessed by means of an ad-hoc form which previously has been utilized and validated in several regional and national surveys [14-16].

2. QOL was evaluated with the Short Form Health Survey (SF-12) [17]. The SF-12 includes the following dimensions: physical activity, physical health limitations on role or activities, emotional state, physical pain, self-evaluation of general state of health, vitality, social activity and mental health. The period of measurement is the previous month. Highest scores correspond to better conditions and QOL.

\section{Ethical Aspects}

The study was approved by the ethical committee of the Italian National Health Institute (Rome). An informed consent was signed by each candidate.

\section{Data Analysis}

Mean and standard deviation of SF-12 score was calculated in the overall sample and in the subgroups divided by sex, age and residence (urban/rural)

Comparisons between and within groups were carried out by means of ANOVA.

\section{RESULTS}

3398 subjects were interviewed (68\% of recruited sample). Details about the total sample and the sample of those interviewed are reported in Tables 1-3.

The mean score of SF-12 in the overall sample was $38.4 \pm 6.1$. Men $(\mathrm{N}=1437)$ showed better subjective QOL than women $(\mathrm{N}=1961)$, scoring $39.6 \pm 6.3$ at $\mathrm{SF}-12$ versus $37.5 \pm 5.9(\mathrm{~F}=99.18$, df 1, 3396, 3397, $\mathrm{p}<0.0001)$. As reported in Table 4, SF-12 scores decreased from the youngest age group ( $<25$ years) to the oldest age group ( $>64$ years), with significant differences between all ages groups. This trend was similar in both men and women (Table 5), but with higher 
Table 2. Enrolled aample by Aage, sex and the Non-Interviewed Rate

\begin{tabular}{|c|c|c|c|c|c|c|c|c|}
\hline Age & $\begin{array}{l}\text { Interviewed } \\
\text { Males }\end{array}$ & $\%$ of Total & $\begin{array}{c}\text { Non- } \\
\text { Interviewed }\end{array}$ & $\begin{array}{l}\text { \% of Non- } \\
\text { Interviewed }\end{array}$ & $\begin{array}{l}\text { Interviewed } \\
\text { Females }\end{array}$ & $\%$ of Total & $\begin{array}{c}\text { Non-Interviewed } \\
\text { Females }\end{array}$ & $\begin{array}{c}\% \text { of } \\
\text { Non-Interviewed }\end{array}$ \\
\hline $18-24$ & 192 & 14 & 180 & 48 & 241 & 12 & 97 & 29 \\
\hline $25-44$ & 499 & 35 & 378 & 44 & 614 & 31 & 226 & 27 \\
\hline $45-64$ & 460 & 31 & 287 & 39 & 707 & 37 & 242 & 26 \\
\hline$>64$ & 286 & 20 & 140 & 33 & 399 & 20 & 80 & 17 \\
\hline
\end{tabular}

Table 3. Comparison Between Interviewed and Randomized sub-sSamples

\begin{tabular}{|c|c|c|c|c|}
\hline Age and Sex & Interviewed & Randomized & Chi Square (1DF) & P \\
\hline \hline Male 18-24 & 192 & 372 & 2.5 & 0.10 \\
\hline Male 25-44 & 498 & 876 & 0.6 & 0.42 \\
\hline Male 45-64 & 441 & 728 & 3.2 & 0.09 \\
\hline Male $>64$ & 286 & 426 & 0.39 & 0.53 \\
\hline Female 18-24 & 241 & 338 & 0.45 & 0.51 \\
\hline Female 24-44 & 609 & 835 & 0.005 & 0.81 \\
\hline Female 45-64 & 703 & 945 & 2.3 & 0.12 \\
\hline Female $>65$ & 399 & 479 & \\
\hline
\end{tabular}

Table 4. Distribution of Age and Quality of Life (SF12 Score)

\begin{tabular}{|c|c|c|c|c|c|c|c|c|}
\hline Age & Number (\%) & SF-12 & $\begin{array}{c}\text { F ANOVA (DF) } \\
\text { [Against <25] }\end{array}$ & $\mathbf{P}$ & $\begin{array}{l}\text { F ANOVA (DF) } \\
\text { [Against 25-44] }\end{array}$ & $\mathbf{P}$ & $\begin{array}{c}\text { F ANOVA (DF) } \\
\text { [against 45-64] }\end{array}$ & \\
\hline$<25$ & 433 & $41.0 \pm 5.8$ & Pivot & ----- & -------- & -------- & ---------- & --------- \\
\hline $25-44$ & 1113 & $39.4 \pm 6.2$ & $\begin{array}{c}21.5 \\
(1,1544,155) \\
\end{array}$ & $<0.0001$ & Pivot & -------- & ---------- & ------- \\
\hline $45-64$ & 1167 & $38.1 \pm 5.8$ & $\begin{array}{c}80.0 \\
(1,1958,1959)\end{array}$ & $<0.0001$ & $\begin{array}{c}26.8 \\
(1,2278,2279)\end{array}$ & $<0.0001$ & Pivot & -------- \\
\hline$>64$ & 685 & $35.7 \pm 6.8$ & $\begin{array}{c}180.2 \\
(1,1116,1117)\end{array}$ & $<0.0001$ & $\begin{array}{c}140.2 \\
(1,1796,1797)\end{array}$ & $<0.0001$ & $\begin{array}{c}65.0 \\
(1,1850,1851)\end{array}$ & $<0.0001$ \\
\hline Total & 3398 & $38.4 \pm 6.1$ & $\begin{array}{c}39.2 \\
(3,3394,3397)\end{array}$ & $<0.0001$ & --------- & & & \\
\hline
\end{tabular}

Table 5. Distribution of Age, Gender and Quality of Life (SF12 Score)

\begin{tabular}{|c|c|c|c|c|c|c|}
\hline Age & Male s Number (\%) & SF-12 Score & Females Number (\%) & SF-12 Score & Anova F (DF) & $\mathbf{P}$ \\
\hline$<25$ & 192 & $42.4 \pm 6.1$ & 241 & $39.8 \pm 5.6$ & $\begin{array}{c}19.4 \\
(1,431,432) \\
\end{array}$ & $<0.0001$ \\
\hline $25-44$ & 499 & $40.2 \pm 6.1$ & 614 & $38.8 \pm 6.1$ & $\begin{array}{c}14.5 \\
(1,1111,1112)\end{array}$ & $<0.0001$ \\
\hline $45-64$ & 460 & $39.1 \pm 5.9$ & 707 & $37.5 \pm 5.8$ & $20.9(1,1165,1166)$ & $<0.0001$ \\
\hline$>64$ & 286 & $37.5 \pm 7.3$ & 399 & $34.4 \pm 6.0$ & $\begin{array}{c}37.4 \\
(1,683,684)\end{array}$ & $<0.0001$ \\
\hline Total & 1437 & $39.6 \pm 6.3$ & 1961 & $37.5 \pm 5.9$ & $\begin{array}{c}99.2 \\
(1,3396,3397)\end{array}$ & $<0.0001$ \\
\hline $\begin{array}{l}\text { Between } \\
\text { gender }\end{array}$ & $\begin{array}{c}F=25.47 \mathrm{DF} \\
(3,1433,1436) \\
\mathrm{P}<0.0001\end{array}$ & & $\begin{array}{c}\mathrm{F}=58.55 \mathrm{DF} \\
(3,1957,1960) \\
\mathrm{P}<0.0001\end{array}$ & & & \\
\hline
\end{tabular}


Table 6. Distribution of Urban/Rural Residence, Age, Gender (Female) and Quality of Life (SF12 Score)

$\left.\begin{array}{|c|c|c|c|c|c|c|}\hline \text { Age } & \text { Urban Number (\%) } & \text { SF-12 score } & \text { Rural Number (\%) } & \text { SF-12 score } & \text { F (df) } & \text { p } \\ \hline \hline<25 & 134 & 40.3 \pm 4.6 & 99 & 39.3 \pm 7.1 & 1.70 \\ (1,231,232)\end{array}\right)$

Table 7. Distribution for Urban Rural Residence age, gender (Males) and quality of life (SF12 score)

\begin{tabular}{|c|c|c|c|c|c|c|}
\hline Age & Urban Number (\%) & SF-12 score & Rural Number (\%) & SF-12 Score & & \\
\hline $45-64$ & 302 & $38.7 \pm 5.8$ & 158 & $39.9 \pm 6.1$ & $\begin{array}{c}4.3 \\
(1,458,459)\end{array}$ & 0.039 \\
\hline Total & 957 & $39.3 \pm 6.3$ & 482 & $40.3 \pm 6.2$ & $\begin{array}{c}8.2 \\
(1,1440,1441)\end{array}$ & 0.004 \\
\hline $\begin{array}{l}\text { Between } \\
\text { residence }\end{array}$ & $\begin{array}{c}\mathrm{F}=30.11 \mathrm{DF} \\
(3,953,956) \\
\mathrm{P}<0.0001\end{array}$ & & $\begin{array}{c}\mathrm{F}=3.86 \mathrm{DF} \\
(3,456,479) \\
\mathrm{P}=0.010\end{array}$ & & & \\
\hline
\end{tabular}

scores across all age groups for men as compared with women. Among women, the distribution by age group (Table 6) did not differ according to urban/rural residence. Only elderly women showed a trend towards better QOL in urban areas,s but the difference between urban and rural mean scores of SF-12 did not reach statistical significance. Young men with urban residence had higher SF-12 scores than their counterparts with rural residence (Table 7). Men with $>65$ years of age living in rural areas showed, by contrast, higher scores than men from the same age group with urban residence (Table 7).

\section{DISCUSSION}

The results of our study can be summarized as follows:

1. Men enjoy a higher subjective QOL than women;

2. Subjective QOL decreases with age in both genders;

3. Men are more sensitive to urban/rural residence than women;

4. Young men live better in cities, elderly men better in rural areas.

Due to the lack of comparable international studies it is hard to interpret the gender differences shown in this study.
Therefore, we cannot say whether these differences are characteristic for Italy or whether they could be found in other countries as well. The ESEMED study carried out a nationwide survey in Italy, Belgium, France, Germany and Spain using SF-12 but the data concerning the national and sex difference on SF-12 have not been published [18]. Interestingly, in a recent paper the impact of gender discrimination on individual life satisfaction was analyzed with a crosssectional model of 66 countries, using the CingarelliRichards Human Rights Database [19]. In contrast to the present results, in this cross-sectional survey being man was associated with less life satisfaction, but in agreement with our survey men aged 65 years and older showed less life satisfaction. Overall, men and women are more satisfied with their lives when societies become more equal. Disaggregated analysis suggests that women, contrary to men, are more satisfied with increasing equality independent of income and political ideology. Equality in economic and family matters does in general not affect life satisfaction. However, women are more satisfied with their lives when discriminatory practices were less prevalent in the economy 20 years ago [20]. However, as the methodology of the two surveys and the constructs measured (subjective quality of life and life satis- 
faction) are quite different,direct comparison with our findings seems problematic.

Classic and contemporary sociological theories suggest that social interaction differs in rural and urban areas [21]. Intimate, informal interactions (strong ties) are theorized to characterize rural areas while urban areas may possess more formal and rationalized interactions (weak ties). Literature on aging and social support stresses the importance of social interaction as a predictor of health among the aged. Using data from Wave III of the Americans' Changing Lives (ACL) study, the hypothesized differences between informal strong ties and formal weak ties on the subjective well-being of older adults in rural, urban, and suburban areas has been examined. Visiting with friends, neighbors, or relatives turned out to have a stronger positive effect on subjective well-being of older adults living in rural areas than those living in urban areas [21]. The study highlights the role of informal strong ties in increasing subjective well-being. Our results suggest that elderly men probably benefit from strong ties available in rural areas more than elderly women and young men.

Technological changes and improved electronic communications seem, paradoxically, to be making cities more, rather than less, attractive for young people, particularly young men. For example, at the time of the survey (20082009 ) in Italy only $40 \%$ of rural areas were covered by the Internet as compared to $100 \%$ of urban areas [22]. In fact, the historical sociology on social interaction does not take into account that nowadays the socialization of young people happens to a considerable extent through the Internet. Another point is that most opportunities for formal and informal non-internet socialization such as schools, discotheques, etc., are located in urban areas [23].

There is a strong correlation between urbanization and economic development across countries, and within-country evidence suggests that productivity rises in dense agglomerations. But urban economic advantages are often offset by the perennial urban curses of crime, congestion and contagious disease [24]. Probably these disadvantages affect more elderly men, the fact that women seem to be less sensitive to these factor needs further analysis [25].

In conclusion one may hypothesize that older men benefit more from informal social support characteristic of the life in rural areas while young men benefit more from the new opportunities of the cities.

\section{LIMITATIONS}

Our study has some significant limitations. First, the observational methodology of epidemiological studies can be ineffective in verifying hypotheses. Thus, the results of our study can only be viewed as a source for generating hypotheses and must be considered as a heuristic contribution stimulating future research in the field. In addition, the results of the univariate analyses conducted for the purposes of the study, indicating gender, age, and urban/rural living as determinants of subjective QOL, have to be considered as preliminary as further analyses of their inter-relationship and the role of co-factors associated with these variables (e.g., differences in mental health and physical health, co-influence of the same factors) are necessary.

\section{CONFLICT OF INTEREST}

The authors confirm that this article content has no conflicts of interest.

\section{ACKNOWLEDGEMENT}

Declared none.

\section{REFERENCES}

[1] Cella DF. Quality of life: Concepts and definition. J Pain Symptom Manage 1994; 9:186-92.

[2] Carta MG, Hardoy MC, Pilu A, et al. Improving physical quality of life with group physical activity in the adjuntive treatment of major depressive disorder. Clin Pract Epidemiol Ment Health 2008; 4(1): 1 .

[3] Bazzichi L, Maser J, Piccinni A, et al. Quality of life in rheumatoid arthritis: impact of disability and lifetime depressive spectrum symptomatology. Clin Exp Rheumatol 2005; 23(6): 783-8.

[4] European Foundation for the Improvement of Living and Working Conditions, Quality of life in Europe, First European Quality of Life Survey 2003, Luxembourg: Office for Official Publications of the European Communities, 2004.

[5] Mura G, Bhat KM, Pisano A, Licci G, Carta M. Psychiatric symptoms and quality of life in systemic sclerosis. Clin Pract Epidemiol Ment Health 2012; 8: 30-5.

[6] Carta MG, Mura G, Sorbello O, Farina G and Demelia L. Quality of Life and Psychiatric Symptoms in Wilson's Disease: the Relevance of Bipolar Disorders. Clin Pract Epidemiol Ment Health 2012; 8: 102-9.

[7] Carta MG, Kovess V, Hardoy MC, et al. Psychosocial wellbeing and psychiatric care in the European Communities: analysis of macro indicators. Soc Psychiat Psychiatr Epidemiol 2004; 39(11): 883-92.

[8] Mantovani G, Astara G, Lampis B, et al. Evaluation by multidimensional instruments of heath-related quality of life of elderly cancer patients undergoing three different "psychosocial" treatment approaches. A randomized clinical trial. Support Care Cancer 1996; 4(2):129-40.

[9] Mantovani G, Astara G, Lampis B, et al. Impact of psychosocial intervention on the quality of life of elderly cancer patients. Psychooncology 1996; 5: 127-35.

[10] Golden J, Conroy RM, Bruce I, et al.The spectrum of worry in the community-dwelling elderly. Aging Ment Health 2011; 15(8): 98594.

[11] Hardoy MC, Carta MG, Marci AR, Carbone F et al. Exposure to aircraft noise and risk of psychiatric disorder: the Elmas survey. Soc Psychiat Psychiatr Epidemiol 2005; 40(1): 24-6.

[12] Carta MG, Sorbello O, Moro MF, et al. Bipolar disorders and Wilson's disease. BMC Psychiatr 2012; 12(1): 52.

[13] Canadian Population Health Initiative, How healthy are rural Canadians, Canadian Institute for Health Information, Ottawa, 2006.

[14] Carta MG, Aguglia E, Bocchetta A, et al. The Use of Antidepressant Drugs and the Lifetime Prevalence of Major Depressive Disorders in Italy. Clin Pract Epidemiol Ment Health 2010; 6: 94-100.

[15] Carta MG, Hardoy MC, Garofalo A, et al. Association of chronic hepatitis $\mathrm{C}$ with major depressive disorders: irrespective of interferon-alpha therapy. Clin Pract Epidemol Ment Health 2007; 3: 22.

[16] Carta MG, Aguglia E, Balestrieri M, et al. The lifetime prevalence of bipolar disorders and the use of antidepressant drugs in bipolar depression in Italy. J Affect Disord 2012; 136(3): 775-80.

[17] Ware J Jr, Kosinski M, Keller SD. A 12-Item Short-Form Health Survey: construction of scales and preliminary tests of reliability and validity. Med Care 1996; 34(3): 220-33.

[18] König HH, Heider D, Lehner T, et al. t, Health status of the advanced elderly in six european countries: results from a representative survey using EQ-5D and SF-12 Health Qual Life Outcomes 2010; 8: 143.

[19] The CIRI Human Rights Data Project, Available at: http://ciri.binghamton.edu/, Revised 2012.

[20] Fischer JAV, Bjørnskov C, Dreher A. On Gender Inequality and Life Satisfaction: Does Discrimination Matter? (April 2007). University of St. Gallen, Economics Discussion Paper No. 2007-07. 
Available at SSRN: http://ssrn.com/abstract $=980629$ or Available at: http://dx.doi.org/10.2139/ssrn.980629.

[21] Mair CA, Thivierge-Rikard RV. The strength of strong ties for older rural adults: regional distinctions in the relationship between social interaction and subjective well-being. Int. J Aging Hum Dev 2010; 70(2): 119-43.

[22] ISTAT, Sistema di Indicatori terriotoriali, Available at: http://sitis.istat.it/sitis/-html/, 2012.
[23] Carta MG, Mura G, Lecca ME, et al. Decreases in depression over 20years in a mining area of Sardinia: Due to selective migration? J Affect Disord 2012; 141(2-3): 255-60.

[24] Glaeser E. Cities, productivity, and quality of life. Science 2011; 333(6042): 592-4.

[25] Sharkey JR, Johnson CM, Dean WR. Relationship of household food insecurity to health-related quality of life in a large sample of rural and urban Women Health 2097; 51(5): 442-60.

Received: August 05, 2012

Revised: August 12, 2012

Accepted: August 20, 2012

(C) Carta et al.; Licensee Bentham Open.

This is an open access article licensed under the terms of the Creative Commons Attribution Non-Commercial License (http://creativecommons.org/licenses/by-nc/3.0/) which permits unrestricted, non-commercial use, distribution and reproduction in any medium, provided the work is properly cited. 